\title{
The Inadequacy of the Y-axis of Growth (SNGn) for the Vertical Pattern Assessment in Patients with Sagittal Discrepancies
}

\author{
${ }^{1}$ Luiz Renato Paranhos, ${ }^{2}$ Tiago Monteiro Brando, ${ }^{3}$ Armando K Kaieda, ${ }^{4}$ Adilson Luiz Ramos, ${ }^{5}$ Fernando César Torres
}

\begin{abstract}
Aim: The aim of this cephalometric study was to evaluate the influence of the sagittal skeletal pattern on the ' $Y$-axis of growth' measurement in patients with different malocclusions.

Materials and methods: Lateral head films from 59 patients (mean age $16 \mathrm{y} 7 \mathrm{~m}$, ranging from 11 to 25 years) were selected after a subjective analysis of 1630 cases. Sample was grouped as follows: Group 1 - class I facial pattern; group 2 - class II facial pattern; and Group 3 - class III facial pattern. Two angular measurements, SNGoGn and SNGn, were taken in order to determine skeletal vertical facial pattern. A logistic regression with errors distributed according to a binomial distribution was used to test the influence of the sagittal relationship (Class I, II, III facial patterns) on vertical diagnostic measurement congruence (SNGoGn and SNGn).
\end{abstract}

Results: Results show that the probability of congruence between the patterns SNGn and SNGoGn was relatively high (70\%) for group 1, but for groups II (46\%) and III (37\%) this congruence was relatively low.

Conclusion: The use of SNGn appears to be inappropriate to determine the vertical facial skeletal pattern of patients, due to Gn point shifting throughout sagittal discrepancies.

Clinical Significance: Facial pattern determined by SNGn must be considered carefully, especially when severe sagittal discrepancies are present.

Keywords: Morphology, Cephalometry, Orthodontics.

How to cite this article: Paranhos LR, Brando TM, Kaieda AK, Ramos AL, Torres FC. The Inadequacy of the Y-axis of

\footnotetext{
1,4,5 Associate Professor, ${ }^{2,3}$ Student

${ }^{1}$ Department of Dentistry, Federal University of Sergipe, UFS Sergipe, Brazil

${ }^{2}$ Department of Orthodontics, Methodist University of São Paulo, Brazil

${ }^{3}$ Department of Public Health, Piracicaba Dental School Unicamp, São Paulo, Brazil

${ }^{4}$ Department of Orthodontics, Maringá University Center, PR Brazil

${ }^{5}$ Department of Division of Orthodontics, University of Sao Paulo City, UNICID, São Paulo, Brazil
}

Corresponding Author: Luiz Renato Paranhos, Associate Professor, Department of Dentistry, Federal University of Sergipe UFS, Sergipe, Brazil, e-mail: paranhos@ ortodontista.com.br
Growth (SNGn) for the Vertical Pattern Assessment in Patients with Sagittal Discrepancies. J Contemp Dent Pract 2014;15(2): 169-173.

Source of support: Nil

Conflict of interest: None declared

\section{INTRODUCTION}

Cephalometry keeps playing a key role in the diagnosis, especially in researches that evaluate the effects of growth and treatments performance. Several analyses were developed to quantity and determine the anterior vertical growth of the face, as for example, the Downs Y-axis of growth of. ${ }^{1}$ But this angle or growth pattern seems to be influenced by the mandibular sagittal length. On the other hand, the angular measurement SnGoGn seems to be safer and independent of mandibular sagittal changes. Other measurements have the same purpose, such as the FMA of Tweed, ${ }^{2}$ Jarabak $^{3}$ quotient and Vert index of Ricketts. ${ }^{4}$

Once the SNGoGn and the SNGn are widely used, and considering the possibility of inaccuracy in the classification of facial type (dolichofacial, mesofacial and brachyfacial), ${ }^{5}$ when a mandibular error is present in the face (class I, II and III facial patterns), this study aimed to verify the probability of matching between SNGn and SNGoGn in different sagittal discrepancies.

\section{MATERIALS AND METHODS}

This study was approved by the Research Ethics Committee of Methodist University of São Paulo, municipality of São Bernardo do Campo (São Paulo State, Brazil), preventing participants and researchers from any ethical or legal inconvenience.

This is an analytical observational study of radiographs and photographs obtained in right lateral view of Brazilian Caucasian individuals, average aged 16 years and 7 months (ranging from 11 to 25 years), with different malocclusions, no history of previous orthodontic treatment, no craniofacial anomalies and no important facial asymmetries. The sample was gathered from the file of the Graduate Program in Dentistry (UMESP), of an universe around 1,630 orthodontic files. 
A Canon digital camera (EOS Digital Rebel XT, Mississauga, Ontario, Canada) was used to obtain the images, with $100 \mathrm{~mm}$ macro lens. The photographs were taken at a distance of $1.5 \mathrm{~m}$ with $1 \times$ adjustment of the macro lens. All patients were instructed to stay at natural head position (NHP) looking at a mirror, with one kilogram weight in each hand and with the cephalostat located in the auricular olives. Patients were asked to remain with the teeth at maximum intercuspation with lips at rest.

A single previously calibrated evaluator from the Master Degree Course in Dentistry examined subjectively the profile photographs of the patients' documentations, separating them into Pattern I, II and III (Skeletal class I, II and III facial patterns), based on a subjective morphological facial analysis. ${ }^{5}$ In this initial selection, the individuals with borderline characteristics have been excluded.

This first subjective analysis considered some important structures of the patient profile such as: straight, concave or convex profile; nasolabial angle; proportion of upper, middle and lower face; chin; mentolabial groove; lips and their relationship; chin-neck line; chin-neck angle; nose line.

After this analysis, the individuals were separated into three groups. In the Pattern I, patients with balanced profile were allocated. Pattern II and III groups were composed by those individuals with evident abnormal sagittal characteristics. Doing this reclassification, the sample was reduced to 574 individuals.

The initial radiographs of these patients were separated and digitized at a resolution of $150 \mathrm{dpi}$, on a range of image size of $100 \%$, and calibrated to 256 shades of grey, in TIFF format, aiming to perform cephalometric analyses. The software used was the Radiocef ${ }^{\mathrm{TM}}$ - (Radiocef Studio 1.0, release 14, Radio Memory Ltd., Belo Horizonte, MG, Brazil).

The cephalometric landmarks used were: A (subspinale); $\mathrm{S}$ (sella); N (nasion); B (supramental); Gn (gnathion); Go (gonium); Prn (middle pronasal); Ls (upper lip), and Sn (subnasal). The angle measurements used were: ANB normative value preset at $2^{\circ}$, according to Riedel, ${ }^{6}$ in 1952; Prn(Sn-Ls) - with value from $90^{\circ}$ to $110^{\circ}$, as suggested by Scheideman et al., ${ }^{7}$ in 1980; SNGn - standard preset at $67^{\circ}$, with variation of plus or minus $3^{\circ}$, as suggested by Steiner, ${ }^{8}$ in 1959; SNGoGn - standard preset at $32^{\circ}$, with variation of plus or minus $5^{\circ}$, as suggested by Riedel, ${ }^{6}$ in 1952.

\section{DETERMINING THE SAGITTAL SKELETAL PATTERN OF THE FACE}

The 574 patients selected were evaluated cephalometrically by the ANB and nasolabial angles. Individuals with ANB $=2^{\circ}$, plus or minus $0.5^{\circ}$, fitted in group I; group II $\mathrm{ANB} \geq 5^{\circ}$; and group III $-\mathrm{ANB} \leq-4^{\circ}$.

The nasolabial angle was used to define sagittal maxillary position. ${ }^{9}$ Scheideman et al. ${ }^{7}$ in 1980 , found a value of $90^{\circ}$ to $110^{\circ}$, from a sample with balanced profile. Considering this, only individuals with nasolabial angle in this range of normality were included in the sample, excluding individuals with maxillary sagittal problems.

After checking the cephalometric measurements of the ANB and nasolabial angles as an exclusion criteria, the sample became to be constituted of only 59 patients.

\section{Determining the Facial Type}

The determination of the facial type was made by two cephalometric measures: SNGn and SNGoGn. When used the SNGn (according to Steiner, 1959) ${ }^{8}$ the facial type was classified as dolichofacial, when equal to or higher than $70.1^{\circ}$, mesofacial when between $64.1^{\circ}$ and $70^{\circ}$, and brachyfacial when the SNGn was lower than or equal to $64^{\circ}$. When used the SNGoGn, the patients were classified as dolichofacial when higher than or equal to $37.1^{\circ}$, mesofacial, between $27^{\circ}$ and $37^{\circ}$, and brachyfacial when lower than or equal to $26.9^{\circ}$, as suggested by Riedel (1952). ${ }^{6}$

\section{STATISTICAL ANALYSIS}

In order to test the hypothesis that the facial type diverges between the two methods, we used a logistic regression with the errors distributed according to a binomial distribution, ${ }^{10}$ verifying thus the probability of matching between the angle measures in the different levels of sagittal discrepancies.

To verify the intra-examiner bias, we used the paired t-test. In the determination of random error, we used the calculation of error proposed by Dahlberg, listed in the Table 1.

\section{RESULTS}

Of the 59 radiographs, 26 were from male patients, and 33 from female. The group of the pattern I was composed of 25 patients (12 females and 13 males), pattern II consisted

Table 1: Mean value, standard deviation of the two measures and paired t-test and Dahlberg error to evaluate the bias and random error

\begin{tabular}{|c|c|c|c|c|c|c|c|}
\hline \multirow[t]{2}{*}{ Measure } & \multicolumn{2}{|c|}{ Measure 1} & \multicolumn{2}{|c|}{ Measure 2} & \multirow[b]{2}{*}{$t$} & \multirow[b]{2}{*}{$p$} & \multirow[b]{2}{*}{ Error } \\
\hline & Mean & $s d$ & Mean & $s d$ & & & \\
\hline ANB & -0.25 & 5.31 & -0.20 & 5.37 & 0.68 & 0.51 & 0.05 \\
\hline Prn. Sn. Ls & 97.88 & 12.70 & 97.90 & 14.19 & -0.02 & 0.98 & 0.02 \\
\hline SNGn & 68.64 & 5.41 & 68.66 & 5.53 & -0.21 & 0.83 & 0.02 \\
\hline SNGoGn & 35.93 & 5.75 & 35.97 & 5.91 & -0.40 & 0.69 & 0.04 \\
\hline
\end{tabular}

NS - nonsignificant difference 
of 15 patients ( 8 females and 7 males), and the pattern III had 19 patients ( 6 females and 13 males). The average age of the patients was 16 years and 7 months.

The matching in the classification between the two cephalometric measures (SNGn and SNGoGn) was used as the response variable. That is, if the classification was the same between SNGn and SNGoGn, the response variable had the value 1 (one). But, if this classification was different, the value of the response variable had the value 0 (zero). Thus, once the response variable is binary (one or zero), we used the binomial distribution. The predictor variable (independent) was the pattern I, II or III. The results of the logistic regression of the matching in the classification as a function of the pattern are shown in the Table 2 .

A marginally significant difference (1) was found between the pattern I and II $(\mathrm{p}=0.06)$, and a significant difference (2) between the pattern I and III $(p=0.01)$. The pattern I is not quoted in the Table 2 because it is the contrast (the Table 2 lists the pattern I minus the pattern II and the pattern I minus the pattern III).

When removed the intercept of the regression, there was a possible matching between the measures (Table 3 ).

This analysis shows the results of the same regression, but without the contrast ${ }^{11}$ among the patterns. With this, the probability of matching between SNGn and SNGoGn for the pattern I was relatively high (1.15 logit, or 70\%) and different from zero (not random). But, for the patterns II and III, this matching is relatively low [pattern II: -0.13 logit (46\%); pattern III: -0.54 logit (37\%)]. Besides, the matching for the patterns II and III is not significant different from zero (i.e. it may be at random - few values of 1 and many values of 0 , as shown in Figure 1 .

\section{DISCUSSION}

Facial and cephalometric analyses are discussed and adopted long ago, ${ }^{12-14}$ since they have a key role in diagnosis, planning and research in orthodontics. ${ }^{15}$

Table 2: Results of the logistic regression of the matching in the classification as a function of the pattern

\begin{tabular}{lllll}
\hline & Estimate & $\begin{array}{l}\text { Standard } \\
\text { error }\end{array}$ & Z value & $r(>|z|)$ \\
\hline Intercept & 1.1527 & 0.4683 & 2.461 & $0.0138^{*}$ \\
Pattern II & -1.2862 & 0.6980 & -1.843 & 0.0654 \\
Pattern III & -1.6917 & 0.6674 & -2.535 & $0.0113^{*}$ \\
\hline
\end{tabular}

*Statistically significant

Table 3: Regression between matching and pattern without the intercept

\begin{tabular}{lllll}
\hline & Estimate & $\begin{array}{l}\text { Standard } \\
\text { error }\end{array}$ & Z value & $\operatorname{Pr}(>|z|)$ \\
\hline Pattern I & 1.1527 & 0.4683 & 2.461 & 0.0138 \\
Pattern II & -0.1335 & 0.5175 & -0.258 & 0.7964 \\
Pattern III & -0.5390 & 0.4756 & -1.133 & 0.2571 \\
\hline
\end{tabular}

The vertical pattern of facial skeleton composes an important aspect by defining the variability in the orthodontic mechanics, as well as in the facial prognosis. Tweed has dictated that the vertical variation in the FMA could define a case as favorable or unfavorable. Ricketts et $\mathrm{al}^{4}$ called the three basic facial types as dolichofacial (vertical growth), mesofacial (balanced growth), and brachyfacial (horizontal growth). Recently, Capelozza Filho ${ }^{5}$ reinforced the importance of the predominance of the facial types on the orthodontic treatment and prognosis. This author related sagittally and vertically the maxillomandibular behavior, suggesting the distinction of five main facial patterns: Pattern I, II, III, long face and short face.

The literature supported by comprehensive cephalometric studies is clear when confirming that the facial pattern is established since the childhood and remains with the growth. ${ }^{1,12,16-19}$ However, in the sagittal direction, the mandibular length is changed with the growth, and varies according to the different sagittal discrepancies.

The SNGoGn angle defines the behavior of the mandibular basis in relation to the cranial base, while the SNGn angle defines the vectorial resultant of the anterior and inferior growth of the mandible. ${ }^{1,20}$ These two measures are usually interpreted together, defining the direction of the facial growth vector. ${ }^{9,21}$ Although the vertical facial pattern is defined early there may be variability of behavior, given the unique and morphogenetic characteristics of each individual. $^{5,16}$

Despite both measures SNGoGn and SNGn (Y-axis) should define the vector of vertical facial growth, classifying thus the patient into mesofacial, brachyfacial and dolichofacial, this does not occurs when there are sagittal errors. In the pattern I, more balanced, the two measures were coincident - in $70 \%$ of cases, but in the pattern II and III, they were coincident only in 46 and $37 \%$, respectively.

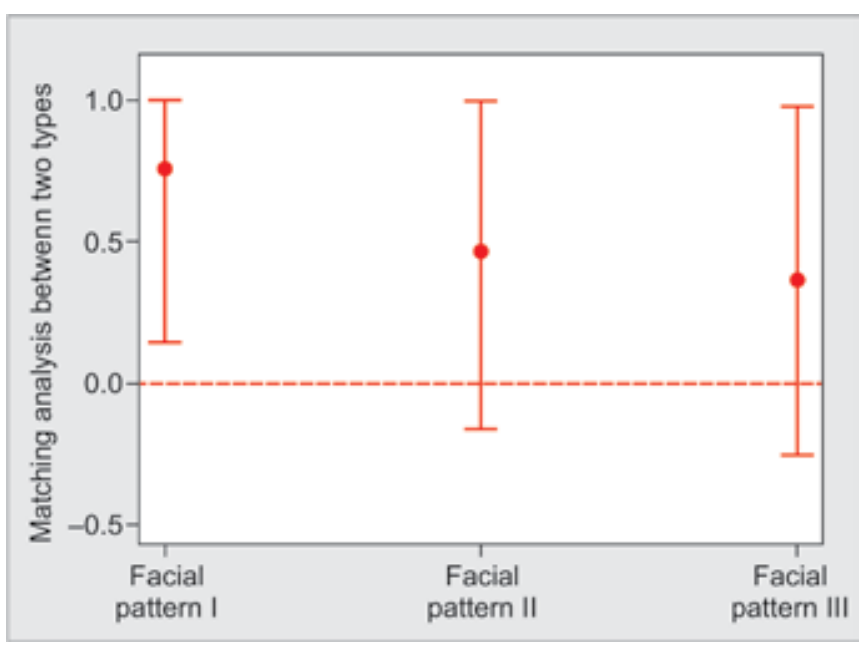

Fig. 1: Proportion of matching in the classification between SNGn and SNGoGn for each pattern 


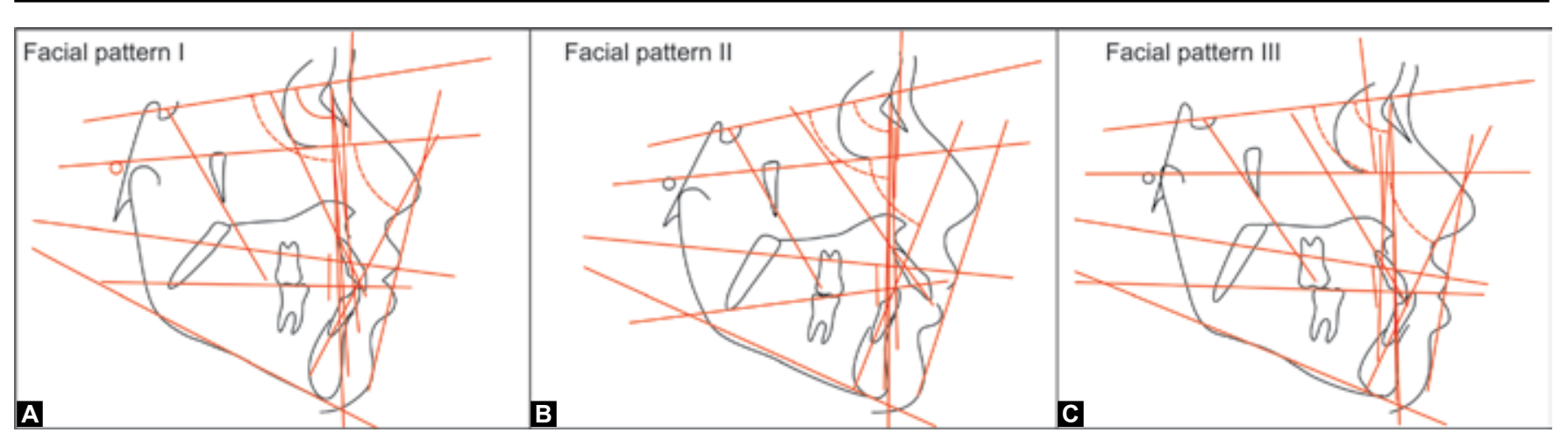

Figs 2A to C: Demonstration of the inadequacy of the Y-axis of growth (SNGn)

for the vertical pattern assessment in patients with sagittal discrepancies

This observational research evidenced the deficiency in the SNGn angle to classify the pattern of vertical growth in patients with remarkable sagittal discrepancy, as shown in Figure 1. The reason is the location of the Gn landmark - in the inferior and anterior portion of the body of the mandible. It is impossible to separate the vertical behavior of the face from the sagittal behavior of the mandible in the interpretation of the growth effects. ${ }^{22}$

Schudy $^{23}$ also reported that the $\mathrm{Y}$-axis of growth is inadequate to express the facial type, corroborating our results, as can be exemplified in Figures $2 \mathrm{~A}$ to $\mathrm{C}$. This author also confirmed that the angles referred the SN line with the mandibular base seem to be the most reliable indicators for the vertical facial variations.

Therefore, the use of the measure SNGn is not appropriate to determine the facial type, due to the influence experienced by the sagittal position of the mandible, even if the face is not vertically changed.

Even being an academic discussion, it is reasonable to check the reliability of the classification of dolichofacial patients (when measured by SNGn), because they can be only pattern II with mandibular retrognathia. And if they had been measured through SNGoGn or similar mandibular, they would be correctly classified as mesofacial, therefore changing the prognosis.

Conversely, dolichofacial and pattern III patients could be maybe erroneously classified as mesofacial, if used the SNGn.

Anyway, the vertical vector requires caution, because it seems to be a variable of limited correction by orthodontic procedures (excluding the procedures combined with orthognathic surgery).

\section{CONCLUSION}

The readings of SNGoGn and SNGn to determine the vertical facial skeletal pattern are matching in $70 \%$ of individuals with no maxillomandibular sagittal error. In the individuals pattern II and III, the matching occurred in only 46 and 37\%, respectively. The $\mathrm{Y}$-axis of growth ( $\mathrm{SNGn}$ ) is inadequate to evaluate the vertical pattern of the head skeleton in patients with large sagittal discrepancies.

\section{REFERENCES}

1. Downs WB. Variations in facial relationships; their significance in treatment and prognosis. Am J Orthod 1948;34: 812-840.

2. Tweed $\mathrm{CH}$. Was the development of the diagnostic facial triangle as an accurate analysis based on fact or fancy? Angle Orthod 1962;48:823-840.

3. Jarabak Jr, Fizzell JA. Aparatologia del arco de canto com alambres delgados: técnica y tratamiento. Buenos Aires: Mundi; 1975;1:p.1263.

4. Ricketts RM. Roth RH, Chaconas SJ, Schulhof RJ, Engel GA. Orthodontic diagnosis and planning: their roles in preventive and rehabilitative dentistry. 1st ed. Denver: Rocky Mountain Orthodontics 1982;1:p.472.

5. Capelozza Filho L. Diagnóstico en Ortodoncia. 1st ed. Maringá: Dental Press 2005;1:p.538.

6. Riedel RA. The relation of maxillary structures to cranium in malocclusion and in normal oclusion. Angle Orthod 1952;22: 142-145.

7. Scheideman GB, Bell WH, Legan HL, Finn RA, Reish JS. Cephalometric analysis of dentofacial normals. Am J Orthod 1980;78:404-420.

8. Steiner CC. Cephalometrics in clinical practice. Angle Orthod 1959;29:8-29.

9. Silva Filho OG, Bertoz FA, Capelozza Filho L, Almada EC. Spontaneous facial growth in pattern II: a longitudinal cephalometric study. Dental Press Ortodon Ortop Facial 2009; 14:40-60.

10. Venables WN, Ripley B. Modern applied statistics with S. Springer: Frankfurt; 4th ed. 2010;1:p.497.

11. Gelman A, Hill J. Data analysis using regression and multilevel/ hierarchical models. 1st ed.: Cambridge University Press 2007.

12. Angle EH. Classification of malocclusion. Dent Cosmos 1899; 41:248-264, 350-357.

13. Broadbent BH. A new X-ray technique and its application to Orthodontics. Angle Orthod 1931;1:45-66.

14. Ricketts RM. Planning treatment on the basis of the facial pattern and an estimate of its growth. Am J Orthod 1957;27: 14-37.

15. Paranhos LR, Benedicto EN, Nunes MF, Kairalla SA, Siqueira DF, Torres FC. Correlation of different cephalometric measurements to define facial type. Int J Orthod Milwaukee 2012;23:31-37 
16. Bishara SE, Jakobsen Jr. Longitudinal changes in three normal facial types. Am J Orthod 1985;88:466-502.

17. Björk A. Cranial base development: a follow-up X-ray study of the individual variation in growth occurring between the ages of 12 and 20 years and its relation to brain case and face development. Am J Orthod 1955;41:198-225.

18. Broadbent BH. The face of the normal child. Angle Orthod 1937; 7:183-208.

19. Tweed CH. The Frankfort-mandibular plane angle in orthodontic diagnosis, classification, treatment planning and prognosis. Am J Orthod Oral Surv 1946;32:175-230.
20. Steiner CC. Cephalometrics for you and me. Am J Orthod 1953; 39:729-755.

21. Bishara SE, Augspurger EF Jr. The role of mandibular plane inclination in orthodontic diagnosis. Angle Orthod 1975;45: 273-281.

22. Klocke A, Nanda RS, Kahl-Nieke B. Skeletal Class II patterns in the primary dentition. Am J Orthod Dentofacial Orthop 2002; 121:596-601.

23. Schudy FF. Vertical growth versus anteroposterior growth as related to function and treatment. Angle Orthod 1964;34: $75-93$. 